\title{
THE 1st AFIR INTERNATIONAL COLLOQUIUM
}

The 1st AFIR International Colloquium took place in Paris in April 1990. AFIR is the section of the International Actuarial Association that deals with the "Actuarial Approach to Financial Risk", and it was set up formally at the 23rd International Congress of Actuaries in Helsinki in 1988. French actuaries are substantially concerned with matters of banking and finance, and it was their enthusiasm, in particular that of the Chairman of AFIR, François Delavenne, which stimulated the foundation of AFIR. It was therefore appropriate that the 1st AFIR International Colloquium should take place in the capital of France, a city which has both a very old financial tradition and new and flourishing markets such as the MATIF.

The organisers of the first of a new series of events must always be concerned about whether it will be a success. On this occasion they need not have worried. Over 560 participants from 34 countries attended, and 64 different papers appear in the four bound volumes that were distributed beforehand. Many of the participants and many of the authors were not actuaries, and the Colloquium benefited from the interchange of ideas about financial risk from different disciplines. Although many actuaries in different countries are involved with questions of finance and investment, the world of finance and investment outside the actuarial profession is very large, and among the functions of a Colloquium like this are to introduce the ideas of financial economists to actuaries and to make financial economists aware of the distinctive approach of actuaries to the institutions with which they typically deal - insurance companies and pension funds everywhere, but other financial institutions too in particular countries.

I suspect that a majority of the participants were not themselves 'actuaries of the third kind', but rather had come to see what actuaries of the third kind wrote and talked about.

Well, they know now. The majority of papers were derived from the mainstream of modern financial economics, such as portfolio theory, option pricing, stochastic models for assets, whereas some related to problems of insurance companies, and rather few managed to do both.

The way in which the meetings were organised was much more like that of the International Congresses of Actuaries, rather than of the ASTIN Colloquiums. There were five long sessions, each of three and a half hours, relieved by a coffee break. Each session began with either one talk of about forty minutes or two of twenty minutes each, followed by a lengthy review of the papers under discussion by the Chairman of the meeting. The number of papers discussed in successive sessions were: 7, 16, 15, 10 and 19. (The astute reader will notice that the sum of these numbers is 67 , not 64 ; three papers were attributed each to two sessions.) 
After the coffee break the discussion was opened to the floor. Many authors made short comments and a few took the opportunity to present briefly additional papers which did not appear in the printed volumes. Generally, however, the discussion centred on the talk or talks which had formed the first part of the proceedings.

Such a format meant that most papers received little discussion at all, and most of the large number of participants were listeners rather than speakers. Indeed, those who did do a lot of the speaking seemed to be the same small coterie at each session, who were conducting in public quite an interesting conversation among themselves.

The titles of the five sessions were: Financial institution risks, Rate risk management, New financial markets, Portfolio management and Insurance and finance; these general titles do not give a very clear indication of the actual subject matter.

The papers on Rate risk management were mostly to do with interest rates, yield curves, immunisation and the like, while the papers on New financial markets were mostly about options, futures and portfolio insurance. The other sessions covered a more disparate set of topics.

The afternoon of the third day was devoted to a 'table ronde' or 'workshop' discussion, which I cannot say contributed much to our enlightenment.

It is not possible in a report such as this to review every paper individually, so I shall take the liberty of mentioning those that interested me particularly; others may have found greater interest or inspiration elsewhere.

James Tilley in "A stochastic yield curve model for asset/liability simulations" described how he had fitted a parametric yield curve to the yields on US Government Bonds, using data at 4-weekly intervals, for a little over eight years. After a suitable transformation of the scale, polynomials of orders from 0 to 10 were fitted to the data for each date. Obviously the higher the order of polynomial, the better the fit, but it was found that most of the variation could be explained by a third order polynomial, with additional terms providing relative little improvement in the fit.

So far the paper describes a curve-fitting exercise which has been carried out often in different ways before. The distinctive feature of Tilley's paper is that he then treated the four coefficients of the fitted polynomials as a multivariate time series. After a further suitable transformation, an autoregressive model of order 2 was fitted, in which quite a number of the parameters were not significantly different from zero.

Two questions come to mind: eight years is, for some purposes, rather a short observation period; what would the results have been like if data had been available at annual intervals for a great many more years? And, how does Tilley's model reconcile with the theoretical stochastic models for interest rate movements, discussed by many authors elsewhere?

Christian Walter in “ Mise en évidence de distributions Lévy-stables et d'une structure fractable sur le marché de Paris" introduced the Lévy-stable (or stable Paretian) distributions, which have been used from time to time to describe stock market movements, but which have seemed to find little favour, 
perhaps because of their mathematical intractability. However, recent developments seem to have eased this problem, and Walter includes a very helpful long list of references, which include papers that show how to find the parameters of a stable distribution, and also how to simulate random values from one. Walter uses the first of these to fit parameters to observations from the French Stock Market Indices (MATIF notionnel and CAC40) and finds that a symmetric distribution with a characteristic parameter of about 1.6 to 1.8 fits the observations. (Note that a normal distribution has a characteristic parameter of 2.0, and a Cauchy distribution one of 1.0.)

Although a Gaussian process has often been found to be a good first approximation to describe the movements of security (and often also commodity) prices, investigators have often found evidence of 'fat-tailedness' in the distributions, with occasional exceptionally large values occurring. Stable distributions are one way of providing a better model; fractal Brownian motion provides another (possibly even a fractal stable process); ARCH (autoregressive conditional heteroscedastic) models seem another. This seems a field fit for further investigation.

The paper by Edwin Neave and Ieuan G. Morgan: "A discrete time model for pricing treasury bills, forward and futures contracts" was one of several that used the binomial model for pricing interest rate options, following the style of the seminal paper by Ho and Lee ("Term structure movements and pricing interest rate contingent claims", Journal of Finance, 41, 1011-1029 (1986)). The development of a 'lattice' structure for the possible sample paths of some random variable readily allows for the imposition of constraints of any arbitrary kind, which the analytical technique leading to the Black-Scholes type of valuation formula does not. There is clearly scope for more development along these lines.

Greg Taylor in a substantial paper "The rate of return for discounting non-life assurance loss reserves" described from first principles a general model for the term structure of interest rates, their derivation from market data, and their application to the valuation of portfolios of liabilities. His paper has far wider application than the title indicates, and is almost a monograph on the discounting of liabilities.

A complete contrast was given by Colm Fagan in "Profit reporting and analysis in unit-linked life assurance". A current topic in Britain and Ireland, and possibly in other countries, is the rate at which the profit from insurance operations, whether conventional life assurance, unit-linked assurance or general insurance, should be recognised in company accounts. This is of particular importance where an insurance company is a subsidiary of a non-insurance company, and its accounts are being compared with those of other subsidiaries within the group, whose businesses may be quite different from insurance.

We are familiar in life assurance with the concept that writing a policy introduces a 'valuation strain', which may appear as a loss in the accounts; this may be followed by many years in which profit is released. Zillmerisation is one way of alleviating this strain in respect of acquisition expenses, but it does 
nothing where the valuation basis is, for proper prudent reasons, stronger than the basis on which the premiums were written. It may be unconvincing to the directors of a holding company to be told that the insurance company has written record new business, and therefore made record losses, but that profits will emerge in due course. Fagan's paper addresses the problem of how profits should be recognised in conjunction with sufficient prudence in the valuation.

One of the possible areas of interest for AFIR members is the treatment of an insurance company as a commercial business, the method of financing, the appropriate rate of return on shareholders capital, etc. It is encouraging to see a few papers on these lines, of which Fagan's was one. Another was Richard Derrig's "The development of property-liability insurance pricing models in the United States 1969-1989", which describes the use of the capital asset pricing model (CAPM), arbitrage pricing theory (APT), and options pricing theory (OPT) to the setting of premiums for non-life assurance in a regulated environment. In such an environment the question arises as to what is a 'fair' expected profit on the insurance premium to provide a 'fair' rate of return on shareholders' funds. Derrig's paper gives a substantial review of various approaches to this problem.

Many other papers were of interest. Eduardo Melinsky discussed the problems of "Issue and analysis of bonds in inflationary conditions" in Argentina; Helge Magnussen discussed "Life insurance, inflation and investment" in Norway; and Steen Sorensen discussed the "Development of unit-linked life insurance" in Denmark. Heather McLeod described "The development of a market yield curve: the South African solution", and Andrew Perrins presented a very lucid "Introduction to capital protection strategies".

One interesting paper distributed at the colloquium was by Menachem Berg on "Options strategies for exchange rate risks", in which four different strategies were compared. While in equilibrium each should have the same value, the paper concentrates on the non-equilibrium position to discover what was the most economical strategy for any given set of conditions.

Two lengthy papers were presented by Robert Clarkson: "The measurement of investment risk" and "The assessment of financial risk". Clarkson presents a new approach, which claims to be superior to conventional methods of risk assessment. I have yet to be convinced that his method is anything more than a re-write of conventional utility theory with the names (and sometimes the signs) changed.

Those who attended the 1st AFIR International Colloquium will do well to go back and read or re-read many of the contributed papers. Those who did not may find it worth getting hold of the papers in order to see what went on. Those who are planning to write a paper for the 2nd AFIR International Colloquium in Brighton, which takes place in April 1991, may find inspiration from this first set of papers, but they will need to be quick about it if their paper is to be accepted for that colloquium.

David Wilkie 